\title{
A Morphological and Genetic Mapping Study of White Colony Mutants of Streptomyces coelicolor
}

\author{
By K. F. CHATER \\ John Innes Institute, Colney Lane, Norwich, NOR $70 F$
}

(Accepted for publication 9 March 1972 )

\begin{abstract}
SUMMARY
Fifty whi mutants of Streptomyces coelicolor, having white instead of the wildtype grey colonies, were examined microscopically and genetically. The aerial mycelium structure of the mutants was broadly classified into six types, ranging from the complete absence of any stage of sporulation to the presence of apparently normal spores. Eight map locations were discovered for whi genes, all in previously well-marked regions of the map. Closely linked mutations possessed similar aerial mycelium structure, with few exceptions.
\end{abstract}

\section{INTRODUCTION}

Hopwood, Wildermuth \& Palmer (1970) described a simple visual selection for sporulation mutants of Streptomyces coelicolor: because the wild-type colony turns from white to grey as its spores mature, it was reasoned that colonies remaining white on prolonged incubation might be unable to make mature spores. In that study about one hundred white (whi) mutants were isolated, of which three were chosen for further study because they were apparently defective in the formation or spacing of sporulation septa. The present report describes genetic mapping studies with many of the remaining mutants, and their phenotypic classification by phase-contrast microscopy.

\section{METHODS}

Organisms. All the strains used in this work were ultimately derived from the wild-type Streptomyces coelicolor (S. violaceoruber sensu Kutzner \& Waksman, 1959) strain A3(2) (Hopwood, 1959). All whi mutants were isolated from this strain by Professor D. A. Hopwood, Mrs Helen Palmer and Mrs Helen Wright, either as spontaneous mutants or following ultraviolet irradiation (Hopwood \& Sermonti, 1962) or treatment with $N$-methyl$N^{\prime}$-nitro- $N$-nitrosoguanidine (Delić, Hopwood \& Friend, 1970). The morphologically wildtype, genetically marked strains used for mapping whi mutants are listed in Table $\mathrm{I}$, and the locations on the circular linkage map of all the markers employed are shown in Fig. 5 (inner circle). Genetic symbols, which follow the recommendations of Demerec, Adelberg, Clark \& Hartman (1966), are as listed by Hopwood (1967) and Harold \& Hopwood (1970a). All recombinant derivatives of whi mutants possessed strAr, because this was the only marker available for selection in primary crosses with the prototrophic whi mutants.

Media and general methods of culture and genetic analysis. These were as described by Hopwood (1967) and Hopwood et al. (1970). Scoring of ultraviolet sensitivity of recombinant progeny on replica plates was as described by Harold \& Hopwood (1970 $b$ ). 
Table I. Characteristics of morphologically wild-type strains used for mapping

All strains were of the NF fertility type except A3(2) which is IF (Vivian \& Hopwood, 1970).

Strain
A3(2)
9
35
417
461
782
876
955
1076
1107
1258
A321
J192
J240
V3I
VII
V15I

Genetic markers

Wild-type
hisD 3
pheAI uraAI
hisC9
metB4 pheAI
argAI cysC 3 hisAI mthB2 strAI
argAI cysC 3 hisC9 pheAI proAI strAI
cysAI5 hisAI nicAI pheAI strAI tps-30
argAI serB2 strAI uraAI
cysDI8 hisAI leuB5 strAI
argAI cysC 3 hisC9 proAI strAI uraAI
uraAI
cysDI8 leuB5 strAI
cysDI8 hisD 3 strAI
mthB2 proAI uraAI strAI uvsB6
hisC9 proAI strAI uvsDI8
argAI uvsDI8 strAI

Microscopy. Impression preparations of aerial mycelium were made by touching a glass coverslip on a 5- to 7-day-old colony growing on defined medium. Alternatively, if the aerial mycelium was to be examined in situ, coverslip preparations were made. A sterile coverslip was inserted obliquely into the agar growth medium, and the strain was inoculated in the acute angle so formed. This permitted aerial mycelium to grow against the coverslip, so that when the latter was carefully removed after 5 to 7 days very little disturbance occurred (Williams \& Davies, 1967). Preparations of both kinds were mounted in water and examined and photographed using a Zeiss Photomicroscope II and Ilford Microneg film.

\section{RESULTS}

\section{Phenotypic classification of whi mutants}

All the whi mutants were examined by phase-contrast microscopy, using impression preparations presumably composed largely of aerial mycelium. This process allowed their rough classification into six classes (I-VI) on the basis of aerial mycelium structure, the numerical sequence not necessarily reflecting a temporal sequence of morphogenetic stages. Representative mutants of the various classes were also examined by the coverslip method, which produced less disruption of the fragile aerial parts of the colony.

Class I. Impression preparations of these mutants contained only long, non-helical fibrous hyphae (Fig. I $a, b$ ). At high magnification (Fig. I $b$ ) sporulation septa (Wildermuth \& Hopwood, 1970) were never seen though, as in wild-type, occasional cross-walls were observed in the substrate mycelium in coverslip preparations, suggesting that, had sporulation septa been present, they too would have been visible.

Class II. In impression preparations of class II mutants the aerial hyphae were often curled into long, tight helices (Fig. I $c$ ), which never showed fragmentation, or any sign at high magnification of sporulation septa (Fig. I $d, e, f$ ). The frequency of helical pieces of mycelium varied considerably among mutants and preparations.

Class III. These mutants resembled the mutant whi-46 described by Hopwood et al. (1970), who observed that impression preparations contained 'unfragmented helical hyphae'. 

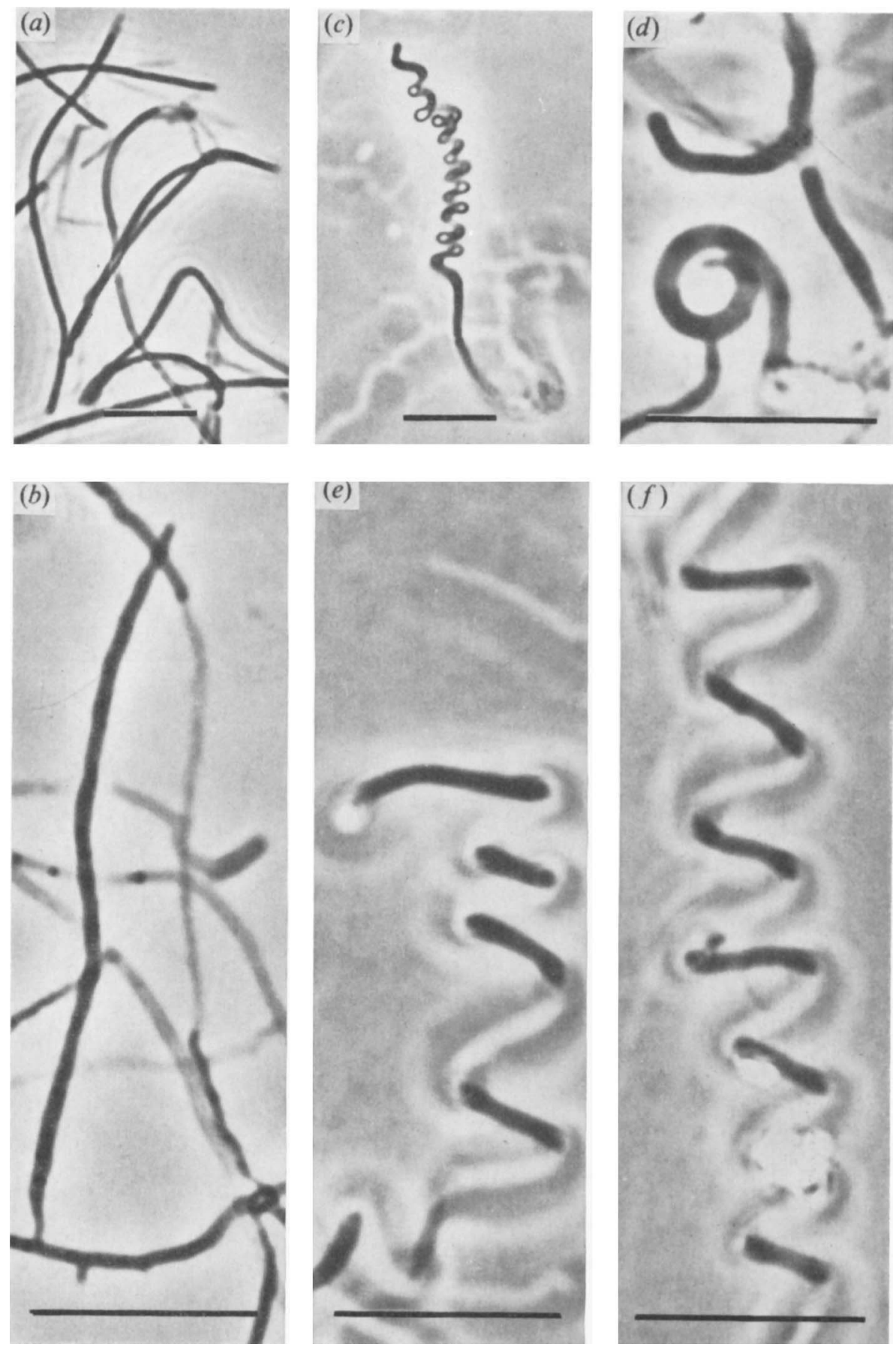

Fig. I. Aerial mycelium of whi mutants (phase contrast). Scale marks represent $10 \mu \mathrm{m}$. (a) and (b) Class I mutants: (a) whi-103; (b) whi-75. Note absence of helical coiling, fragmentation and sporulation septa. (c) and (d) Class II mutant (whi-7o). Note tight helical coiling but absence of fragmentation and sporulation septa. $(e)$ and $(f)$ Class II mutant (whi-72). High magnification photomicrographs showing absence of sporulation septa in helical regions. 

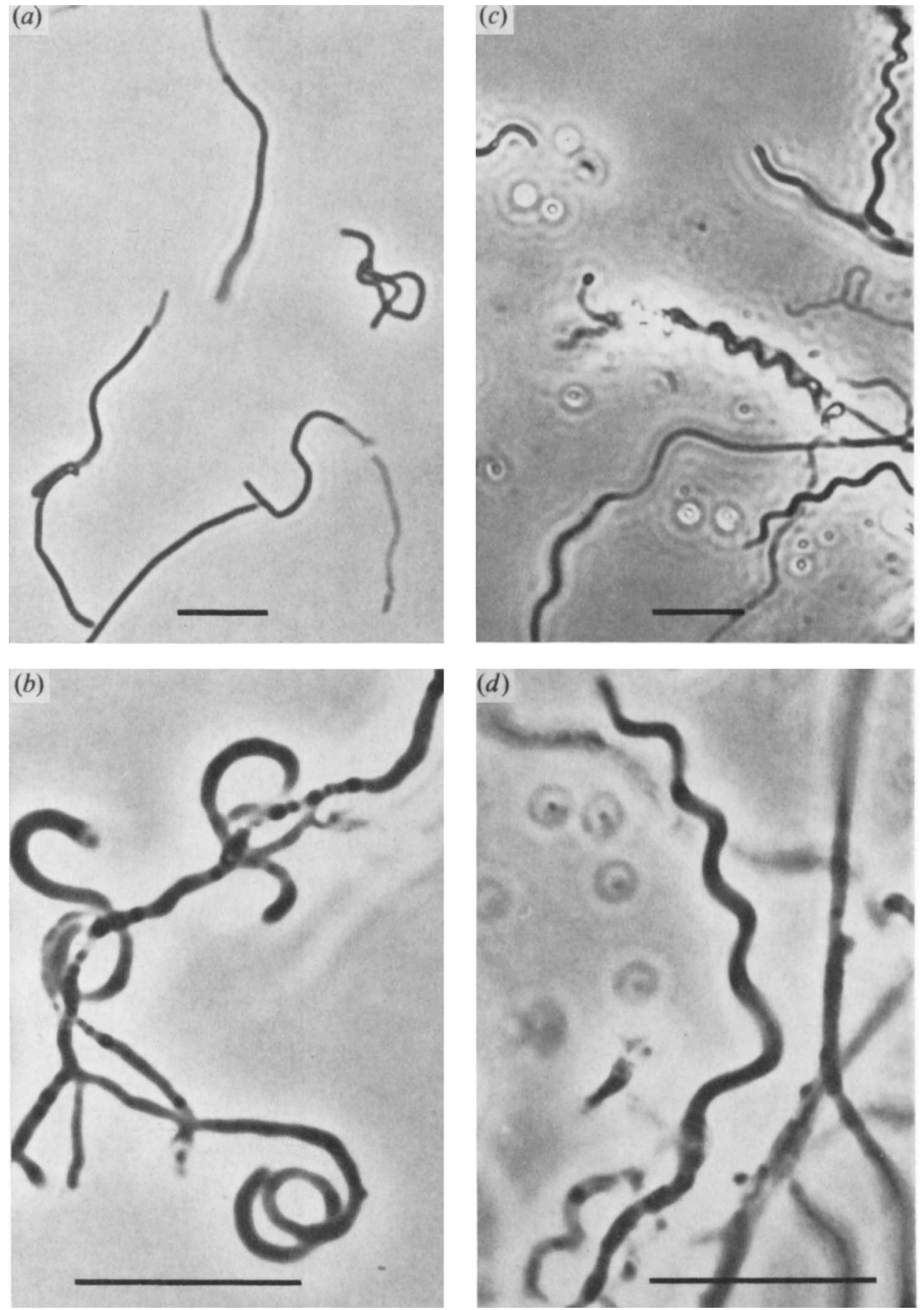

Fig. 2. Aerial mycelium of whi mutants (phase contrast). Scale marks represent Io $\mu \mathrm{m}$. (a) and (b) whi-r93. Note irregular coiling but absence of fragmentation and sporulation septa. (c) and $(d)$ Class III mutant (whi-119). Hyphae are wavy and do not fragment or make sporulation septa. 
The pitch of the helices was longer than in class II mutants, giving the aerial mycelium a wavy rather than spring-like appearance (Fig. $2 c, d$ ). Sporulation septa were not seen at high magnification (Fig. 2d).

One mutant, whi-193, was difficult to classify, having features of each of groups I and III. Its aerial hyphae never fragmented, and occasionally formed irregular helices (Fig. 2a, b) apparently having no sporulation septa. Small numbers of spores were sometimes encountered, their frequency increasing with colony age.

Class IV. The mutants whi-6 and -13 of Hopwood et al. (I970) were both members of this class, which comprised those mutants producing many short, often tightly coiled, fragments in impression preparations, occasionally with some spores (Fig. $3 b$ ). From coverslip preparations (Fig. 3a,c) it appeared that in situ the aerial hyphae consisted of a short stem of straight mycelium, in which widely spaced cross-walls could occasionally be seen, surmounted by a tightly coiled terminal knot within which closely spaced sporulation septa were often discernible. It was presumably at these septa that fragmentation, observed in impression preparations, took place. In the particular case of whi-r 3 , although fragmentation occurred, there was also some resemblance to class II mutants in that long tightly coiled helical hyphae apparently lacking sporulation septa were often seen.

Class V. Only one class V mutant (whi-99) has been identified. It produced regular chains of spore-like bodies (Fig. $4 a, b$ ) which differed from mature wild-type spores (Fig. $4 d$ ) in being rod-shaped rather than oval. Measurements of the dimensions of these units, made on chains in photomicrographs, gave average dimensions of $0.765 \times 1.64 \mu \mathrm{m}$ (sample size 36) for whi-99 and $0.865 \times \mathrm{I} .26 \mu \mathrm{m}$ (sample size 64 ) for the wild-type. The calculated cytoplasmic volumes of such objects, assuming a spore wall thickness of $0.05 \mu \mathrm{m}$, are 0.39 and $0.32 \mu \mathrm{m}^{3}$ respectively. Thus the difference between the two types is one of shape rather than size. This rod-shape also occurs in immature wild-type spore chains (Fig. $4 d$ ); perhaps whi-99 is unable to perform a 'rounding-up' of spore units.

Class VI. Impression preparations of these mutants contained many spores and sporechains closely resembling those of the wild-type; indeed, those of whi-ro7 and -124 were indistinguishable from wild-type spores. These two mutants may be unable to make the grey pigment of wild-type spores (if the grey colouration is in fact due to a pigment). The spores of whi-16 (Fig. 4c) were more distinctive, being more nearly spherical and slightly larger than wild-type spores and forming somewhat irregular chains. Particles showing Brownian movement were often seen within whi-I6 spores, suggesting that the spores had lost their structural integrity, and that the spore wall might be more fragile in this mutant than in the wild-type.

\section{Genetic analysis of whi mutants}

Because the whi mutants were all isolated directly from the wild-type strain A 3(2), they were all prototrophic, streptomycin-sensitive, and of the 'IF' fertility type (Vivian \& Hopwood, 1970).

In preliminary mapping experiments, each mutant was crossed with one of the multiply marked, streptomycin-resistant strains 876 and 1258 , which were both NF in fertility type (Hopwood, Harold, Vivian \& Ferguson, 1969; Vivian \& Hopwood, 1970). Spore progeny from the cross were plated on a medium containing streptomycin and lacking histidine (or arginine). Only those recombinants that had inherited the his $C^{+}$(or $\arg A^{+}$) allele of the whi parent strain, and the strAI allele of 876 or 1258 , were able to grow on this medium; the remaining growth requirements of 876 or 1258 were present in the medium, permitting the segregation of the other markers present in the cross. 

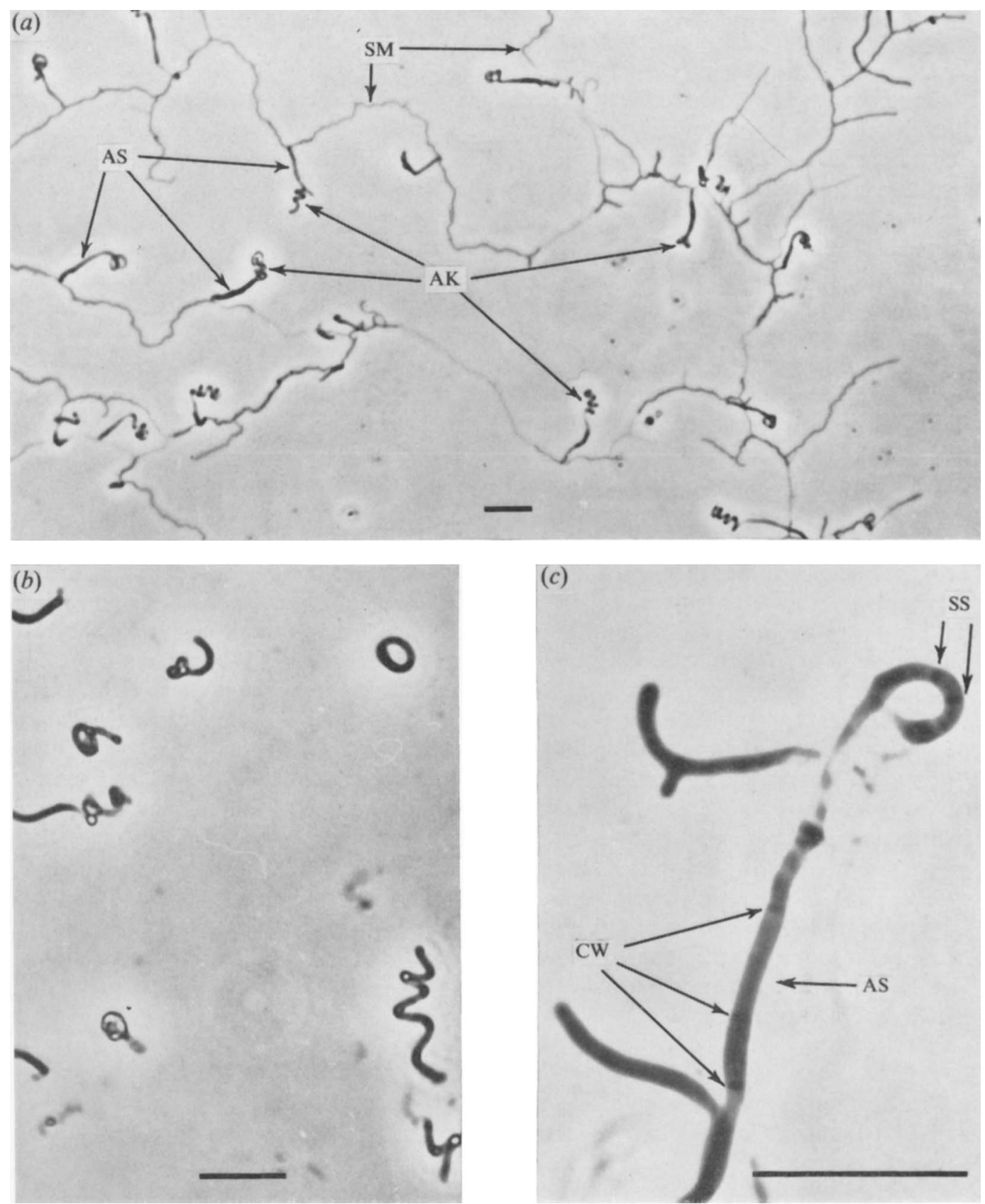

Fig. 3. Aerial mycelium of whi mutants (phase contrast). Scale marks represent $10 \mu \mathrm{m}$. (a) whi-I7, coverslip preparation; (b) whi-229, impression preparation; (c) whi-4o, coverslip preparation. All three mutants are examples of the class IV phenotype. Aerial hyphae growing on the substrate mycelium (SM) have straight stems (AS) containing widely spaced cross-walls (CW); the stems are surmounted by tightly coiled knots (AK) often containing relatively closely spaced sporulation septa (SS). The fragments seen in impression preparations are presumably derived from the knots. 

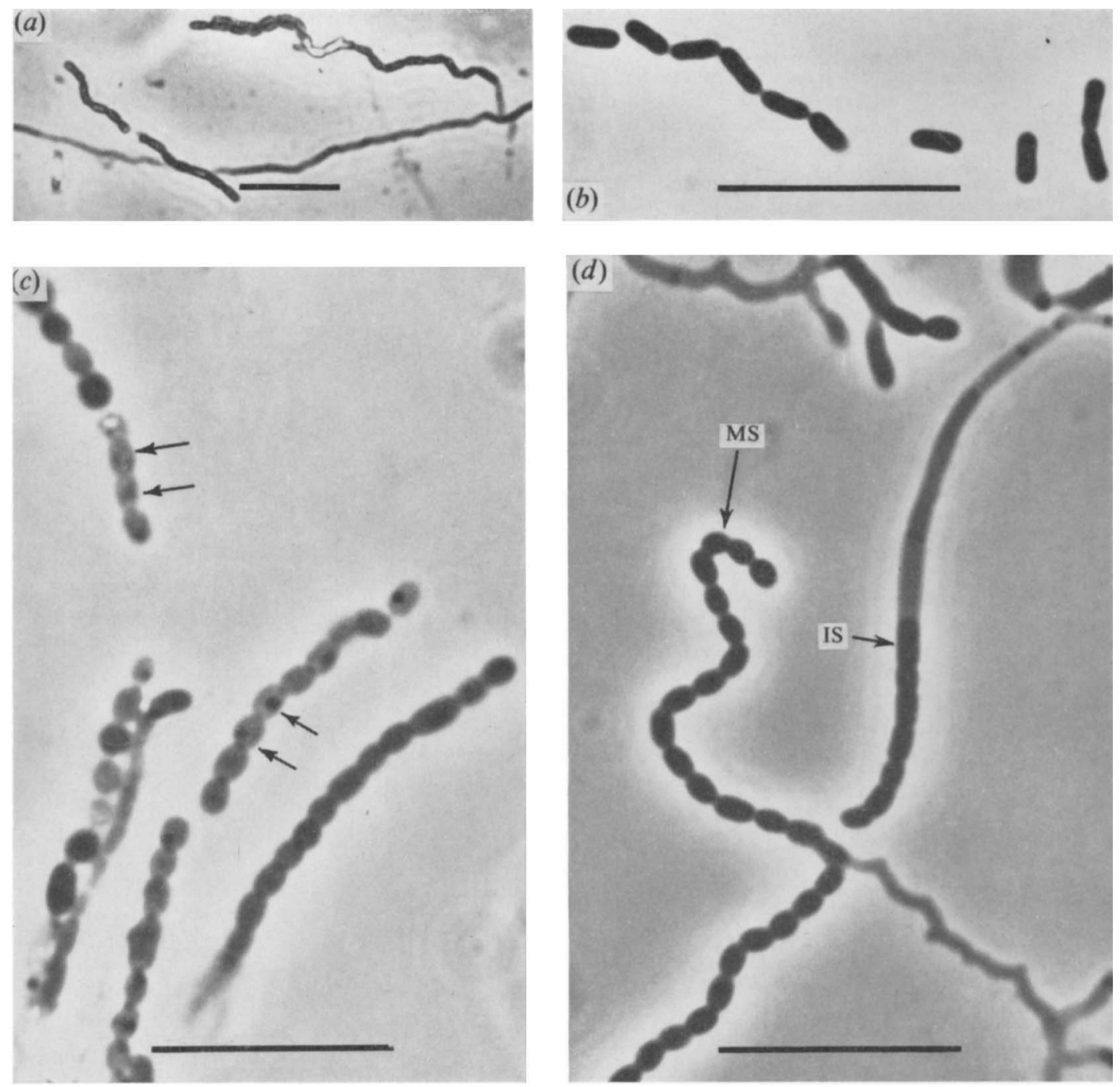

Fig. 4. Spores of whi mutants and the wild-type (phase-contrast). Scale marks represent Io $\mu \mathrm{m}$. (a) and (b) Class V mutant (whi-99). This mutant produces chains of rod-shaped spores. Double chains (a) are also found in the wild-type and in other whi mutants. (c) Class VI mutant (whi-16). The spore chains are irregular and the spores rounder than in the wild-type. Some spores (arrow) are transparent and contain particles showing Brownian movement. Most other class VI mutants possess spores that are indistinguishable from those of the wild-type. $(d)$ Wild-type. Note rod-like appearance of immature spores (IS) and ellipsoidal shape of mature ones (MS).

After scoring of recombinant phenotypes, the frequency of each segregating allele among the recombinants was calculated, and the values inserted in a diagrammatic representation of the cross (Table 2). The frequency of an allele is related to the closeness of its linkage to the selected marker with which it was coupled in the parent strain, so that the frequency of the whi mutation in each cross indicated the closeness of its linkage to his $C^{+}$(or $\arg \mathrm{A}^{+}$) compared with that of other markers in the cross. The whi mutation was thus given two alternative locations, one in each of the arcs separating the selected markers. To decide 


\section{Table 2. Preliminary mapping of whi mutations}

Examples are given of crosses with four genetically distinct whi mutants. Each whi mutant (inner circle in diagrams) was crossed with strain 1258 (outer circle) and $h i s A^{+}$(or $\arg A^{+}$) and strAI (indicated by triangles) were selected. The numbers in the diagrams are the frequencies of alleles among the recombinant progeny. The segregation of each whi mutation with respect to a potentially closely linked marker from each of the arcs separating the selected markers is tabulated below each diagram, and shown to be more dependent upon one marker than on the other. In each cross, one recombinant class out of the eight tabulated should have arisen from multiple crossing over, and therefore be rarer than the other seven. This class in each cross is given in bold-face type.

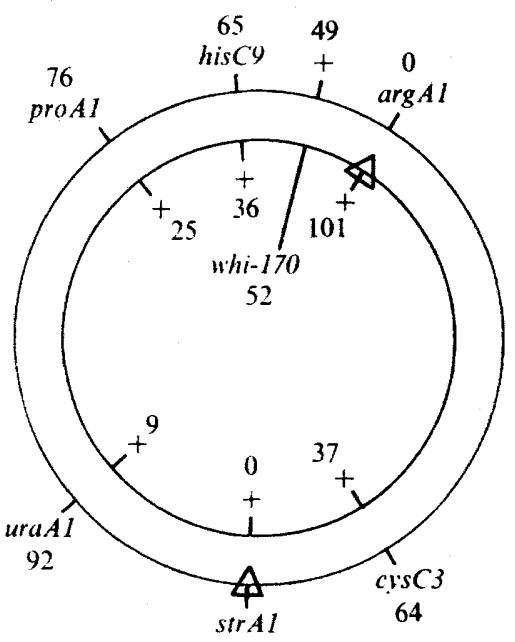

101

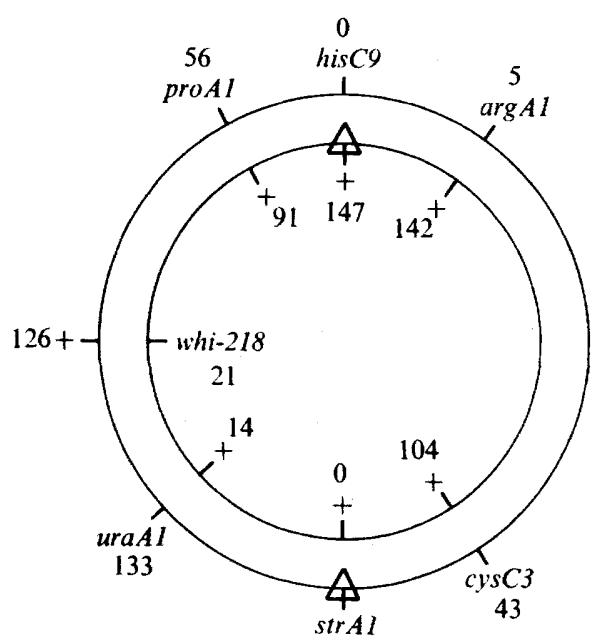

147

$\begin{array}{lcccc} & \text { hisC9 } & \text { his }^{+} & \mathrm{cyc} 3 & \mathrm{cys}^{+} \\ \text {whi-170 } & 16 & 36 & 22 & 30 \\ \text { whit } & 49 & 0 & 42 & 7\end{array}$

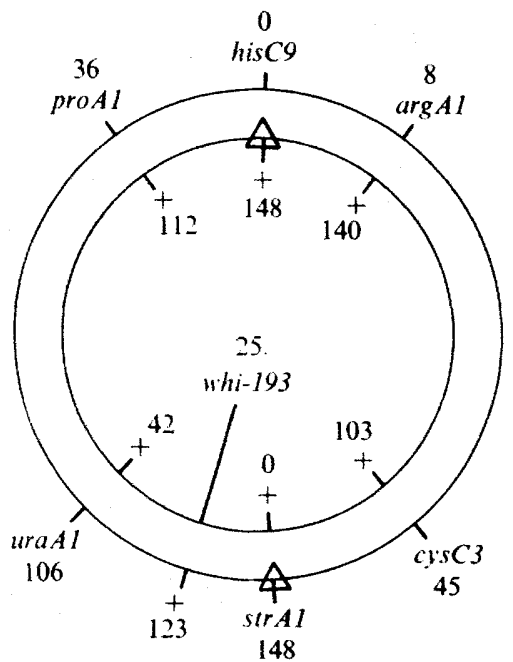

$\begin{array}{lcccc} & \text { uraAl } & \text { ura }^{+} & \text {cysC3 } & \text { cys } \\ \text { whi-2I8 } & 7 & 14 & 9 & 12 \\ \text { whi } & 126 & 0 & 34 & 92\end{array}$

uraAl ura ${ }^{+}$

$\begin{array}{lll}\text { whi-193 } 2 & 23\end{array}$

whi ${ }^{+} \quad 104 \quad 19$ $\mathrm{cyc}^{2} \mathrm{cys}^{+}$

322

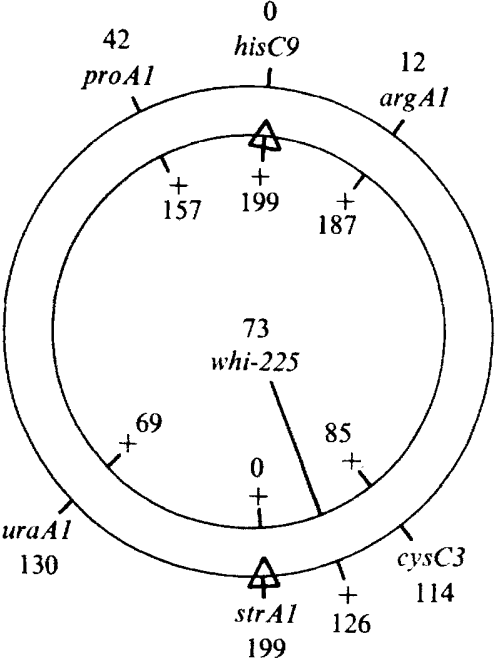

uraAI ura $^{+}$

cysC3 $\mathrm{cvs}^{+}$

whi-225 $25 \quad 48$

whi $^{+} \quad 105 \quad 21$

172

$113 \quad 13$ 
between these locations the segregation of the whi mutation with respect to that of a potentially closely linked marker from each arc was tabulated. In each case, segregation of the whi mutation was far more dependent on the segregation of one marker, to which it was therefore linked, than on that of the other. In the examples given in Table 2, lack of independent segregation was shown by the following pairs of mutations: whi-I 70 and hisC9; whi-2I 8 and $u r a A I$; whi-I93 and uraAI; and whi-225 and cysC3. Among 50 mutations mapped in this way, six were located in the hisC-argA interval, two in the proA-uraA interval, one in the uraA-str $A$ interval, and $4 \mathrm{I}$ between $s t r A$ and $c y s C$. With this information, it was possible to devise further crosses that gave more precise map locations, and allowed the subdivision of some groups of mutants. These crosses will be described under separate headings.

Mutations located between hisC and argA. Six mutations (whi-13, -72, -73, -85, -170 and -213) were located in the his C-arg $A$ interval. Of these, five had the class II phenotype and the sixth, whi-I 3 , the class IV phenotype. Recombinant derivatives were constructed carrying each mutation coupled with his $C 9$ (or the closely linked mutation hisAI) and $\arg A I$ respectively (with the exception that no $\arg A I$ whi-85 or his whi-I 70 recombinants were obtained). Two types of crosses were then made using these strains.

In the first series of crosses, designed to measure recombination between pairs of whi mutations, each whi hisCg (or hisAI) strain was crossed with all the whi argAI strains, and selection was made for his ${ }^{+}$arg $^{+}$recombinants, arising from crossing-over in the his-argA interval. The colonies arising were scored as $w h i$ or $w h i^{+}$by visual examination. The prediction was that $w h i^{+}$recombinants should arise with much higher frequency in one coupling arrangement than in the other for any pair of whi mutations, allowing the sequence of the mutations on the map to be determined. In practice, the frequency of whi+ recombinants was so low (less than $\mathrm{I} \%$ ) that it was difficult to eliminate the possibility that they had arisen from reversion of one of the parent strains to $w h i^{+}$. Thus an unambiguous sequence of mutations could not be obtained: but it was clear that all six mutations were very closely linked.

In the second series of crosses, designed to study recombination between the whi mutations and the $u v s D I 8$ marker also located in the hisC-arg $A$ interval, similar selection was applied (for his ${ }^{+}$and arg $^{+}$), but each cross was between either a whi hisC 9 (or whi hisAI) strain and strain vi5I ( $\arg A I$ uvsDI8), or a whi $\arg A I$ strain and strain vir5 (hisC9 uvsDI8). Because it turned out that the whi mutations were somewhat less closely linked to $u v s D$ than they had been shown to be to each other, the results for all the mutations tested were summed, giving the following totals:

argAI uvs DI $8 \times$ whi his: uvs $D_{I} 8,600 ; u v s D_{I} 8$ whi, 22; whi, 126; uvs $s^{+}$whi $i^{+}, 8$ : hisC9 uvs DI8 $\times$ whi arg: uvs DI8, 309; uvsDI8 whi, 6; whi, 249; uvs ${ }^{+}$whit ${ }^{+}$I7.

These data strongly suggested a location for the whi mutations close to, and clockwise of, the $u v s D$ locus.

It had previously been observed (D. A. Hopwood, personal communication) that the mutant whi-73 was highly u.v.-sensitive, and it was shown by Harold \& Hopwood (I970 b) that it possessed a mutation in the $u v s A$ gene, designated $u v s A 24$, closely linked to $u v s D$. It was thus important to establish whether the uvsA24 mutation was also responsible for the whi-73 phenotype. That this was not the case was shown by the phenotype of the recombinant strain hisC9 whi-73, which had wild-type u.v. sensitivity and mutant morphology. On the other hand, the $\arg A I$ whi-73 recombinant strain used in some crosses was highly u.v.sensitive, and could not be used in the crosses involving uvs DI8. Presumably it had retained 


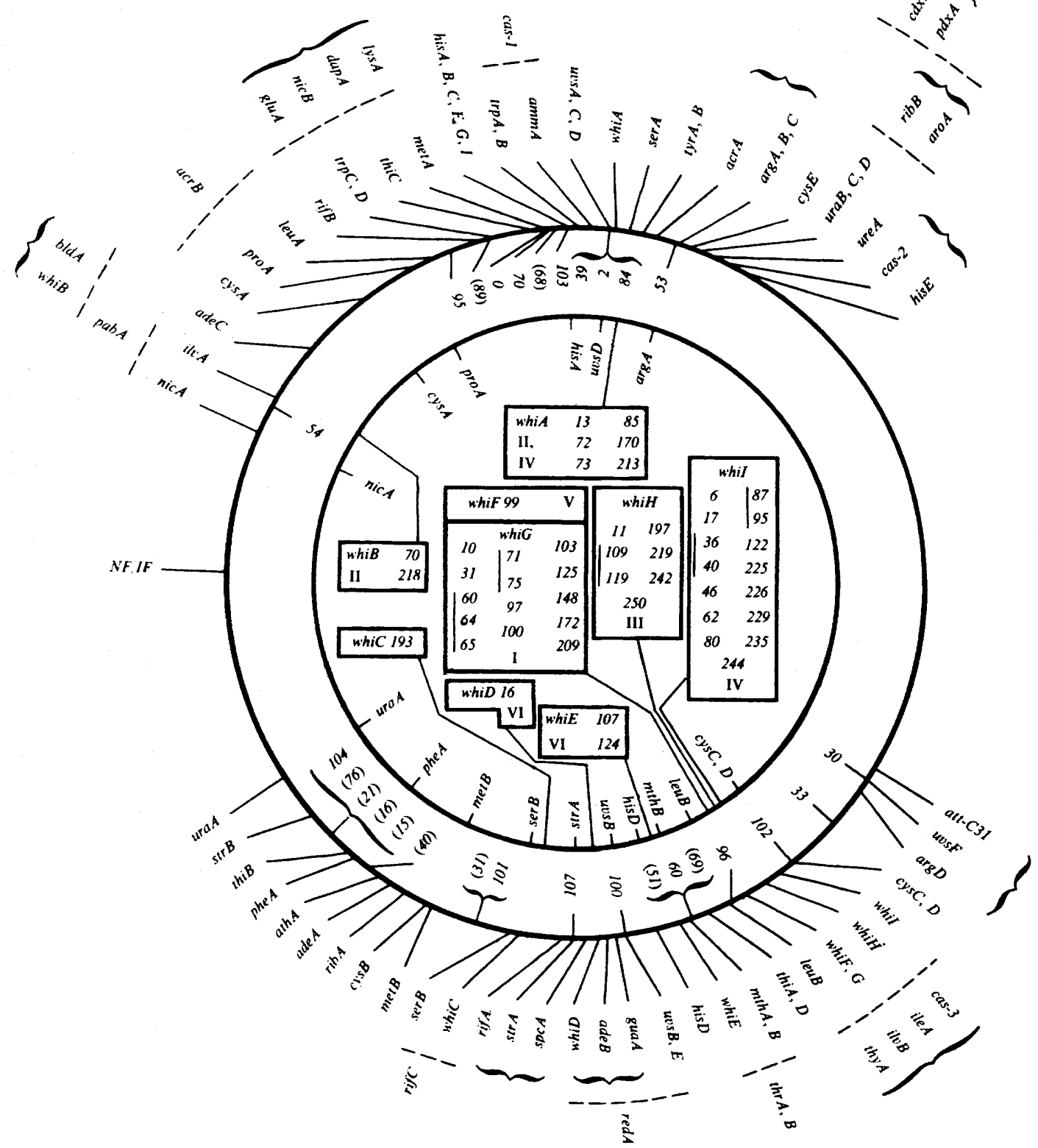

Fig. 5. Linkage map of Streptomyces coelicolor and summary of results in this paper. Outer circle: the outer circle is an up-to-date linkage map of Streptomyces coelicolor redrawn from that of Hopwood (1970) with later additions. The locus designations are as given by Hopwood (1967, 1970) with the following additions: att-C3I, attachment site of prophage $\phi C_{3} I$ (Lomovskaya et al. 197I); bld $A$, apparent absence of aerial mycelium (Hopwood, 1967); NF/IF, donor versus recipient fertility (Vivian \& Hopwood, 197I); rifA,B,C, resistance to rifampicin (K. F. Chater, unpublished); trp $A, B, C, D$, requirement for tryptophan (replaces try) (P. Engel, personal communication). Numbers on the inside of the outer circle represent indispensible temperature-sensitive mutations (Hopwood, 1966), parentheses indicating mutations which have now been lost. The orders within groups of bracketed loci are unknown. Certain loci have not been ordered relative to groups of loci covered by dotted lines. Inner circle: the inner circle gives the locations of markers referred to in this paper, and contains a summary of the locations and phenotypes of the whi mutations examined. Appended to each whi locus is a list of the allele numbers of mutations located there; alleles covered by lines are possibly of clonal origin. The predominant phenotypic classes of whi loci are given in Roman numerals, the meaning of which is described in the text (Results). 
Table 3. More precise location of whi-70 and -218

The whi mutants were crossed with strain 955 , and $h i s A^{+}$and $\operatorname{str} A I$ (indicated by triangles) selected. The number against each allele in the diagrams gives the percentage frequency of that allele among the recombinant progeny. The tabulations of whi against cys $A$ and nic $A$ segregation show the numbers of informative recombinants upon which the presumed location of the whi mutations is based; the rarest class in each tabulation, given in bold-face type, is presumed to have arisen from multiple crossing-over.

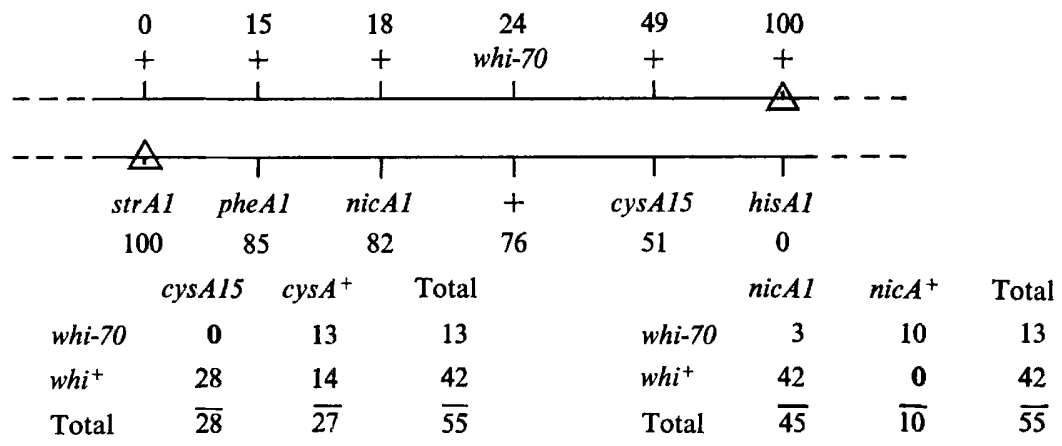

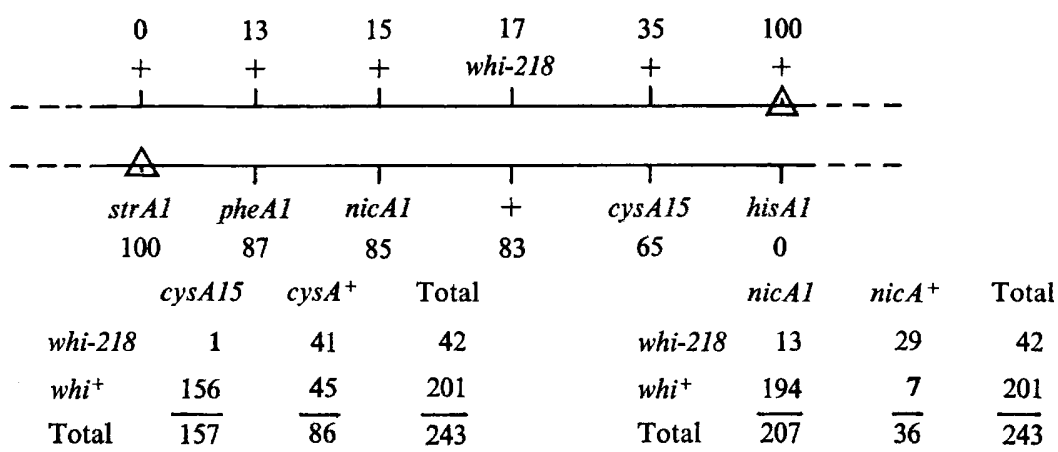

the uvsA24 mutation. The numbers of crossovers required for the formation of the hisC9 whi-73 and $\arg A I$ uvs $A 24$ whi-73 strains are minimized if the map sequence of the $u v s$ and whi genes is as suggested above; on the alternative sequence multiple crossing-over would be required for the formation of the former strain.

The observed frequency of crossing-over between $u v s D$ and the whi mutations was about $3 \%$ in both coupling arrangements. With the same selection, Harold \& Hopwood (1970b) obtained about $15 \%$ recombination between $u v S C A D$ mutations and ser $A$, and up to $5.6 \%$ between mutations within the $u v s C A D$ cluster. The whi mutations are thus located anticlockwise of $\operatorname{ser} A$, and, assuming that the uvsCAD cluster comprises three contiguous genes, the number of genes separating $u v s D$ from the whi mutations is unlikely to be more than one or two.

On the strength of these data, the six whi mutations were assigned to the whiA locus (Fig. 5). whi-7o and -218. The preliminary crosses (Table 2) indicated a location between uraA and proA for the mutations whi-70 and -218 , both of which had class II phenotypes. Further crosses were made with strain 955 , which is well marked in this region, with the results shown in Table 3. Both mutations mapped in the interval between cys $A$ and nicA at about Io o'clock on the linkage map; this was the first location of whi mutations in this region of the map and the locus so defined was termed whiB (Fig. 5). 
Table 4. More precise location of whi-I93

The recombinant strain $m t h B 2$ str $A$ I whi-r 93 was crossed with strains 35,461 and 1076 , selection being applied as indicated by triangles. The number against each allele in the diagrams gives the percentage frequency of that allele among the recombinant progeny. Segregation of strAI was not scored in crosses with strains 35 or 1076 , and the colour of six serB2 colonies in the latter cross was indeterminate.

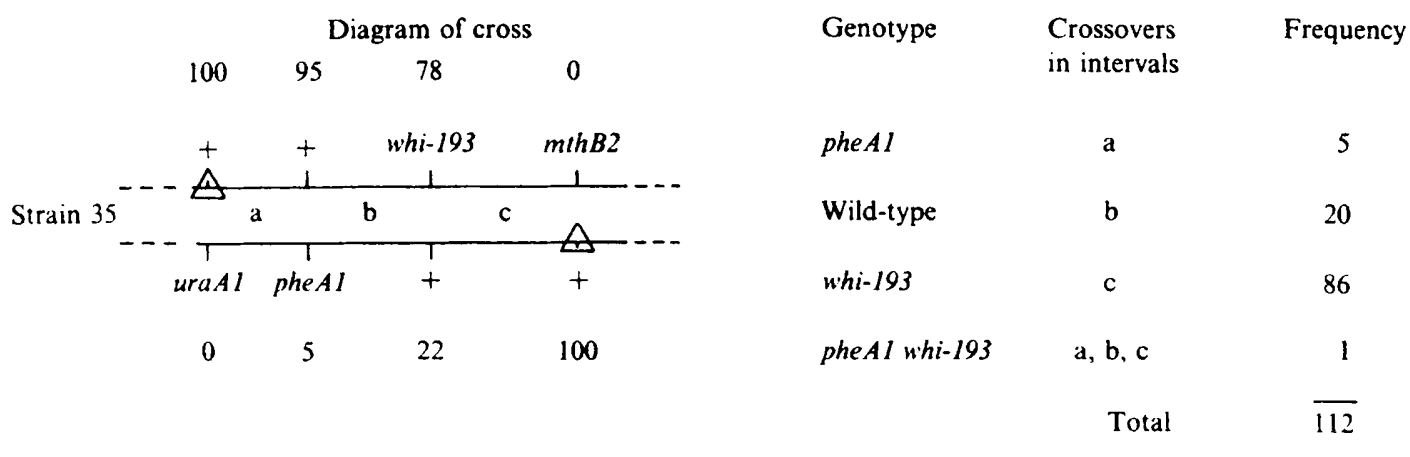

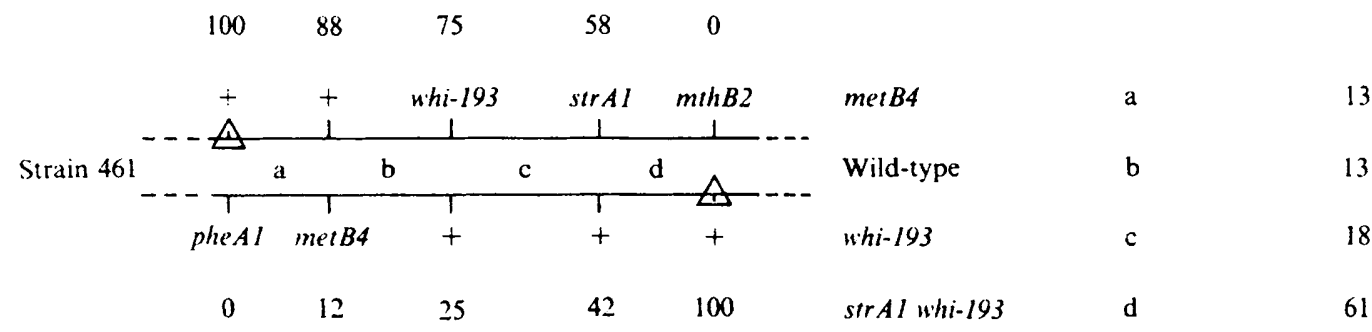

Others $\quad a, b, c ; a, b, d ; b, c, d \quad 0$

Total $\overline{105}$

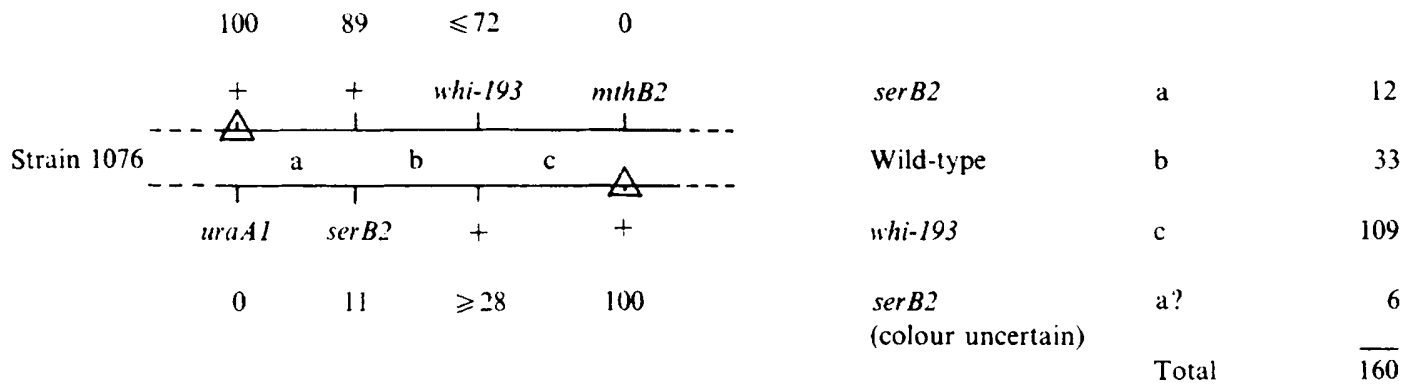

whi-193. Preliminary data located whi-I93 (phenotypic class I or III) between uraA and $\operatorname{str} A$ (Table 2). To refine this mapping, a mthB2 strAI whi-193 recombinant strain was crossed with strains carrying various marker mutations known to be located in the uraA-str $A$ interval (Table 4).

In the first cross, with strain 35 , selection was made for recombinants arising by crossingover between $u r a A$ and $m t h B$, and the segregation of the included marker phe $A I$ was examined in relation to that of whi-r93. $w h i^{+}$phe $A^{+}$recombinants were common, whereas 
Table 5. The location of whi-16

The mutant whi-I6 was crossed with strains 782 and v31, with selection as indicated by triangles, and the allele frequencies (percentage) obtained are shown in the diagrams.

\begin{tabular}{|c|c|c|c|c|c|c|}
\hline & Diagran & of cross & & Genotype & Crossovers & Frequencs \\
\hline 0 & 4 & 91 & 100 & & & \\
\hline+ & whi-16 & + & + & whi-16 & a & 4 \\
\hline$\wedge$ & & b & c & Wild-type & b & 81 \\
\hline str $A I$ & + & ${ }_{m t h B 2}^{1}$ & ${ }_{\text {cysC3 }}$ & $m t h B 2$ & c & 9 \\
\hline 100 & 96 & 9 & 0 & $m$ thB2 whi-16 & $a, b, c$ & 0 \\
\hline & & & & & Total & $\overline{94}$ \\
\hline 0 & 55 & 87 & 100 & & & \\
\hline+ & whi-16 & + & + & whi-16 & a & 56 \\
\hline$-A$ & 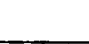 & b & c & Wild-type & b & 35 \\
\hline strAI & + & uvsB6 & $m t h B 2$ & uvsB6 & c & 12 \\
\hline 100 & 45 & 13 & 0 & uvsB6 whi-16 & $a, b, c$ & 2 \\
\hline & & & & & Total & 105 \\
\hline
\end{tabular}

whi-193 pheAI recombinants were rare, showing that the location of whi-193 was anticlockwise of pheA.

In a second cross, with strain $46 \mathrm{I}$, the selection was for recombinants arising from crossing-over between phe $A$ and $m t h B$, and the segregation of the included markers $m t h B 4$ and strAI was examined in relation to that of whi-193. Since whi-I 93 str $A^{+}$recombinants were common, and whi+ strAI recombinants undetected, the location of whi-r93 clockwise of $s t r A$ was confirmed: moreover, the detection of $12 \%$ of whi+ met $B^{+}$, but no whi-193 metB, recombinants showed that whi-I93 was situated anti-clockwise of metB4.

Finally, a cross was made with strain 1076, which carried the serB2 marker located between $m e t B$ and $s t r A$. Selection here was for recombinants arising from crossing-over between uraA and strA. A high proportion (2I \%) of recombinants were $w h i^{+} s e r B^{+}$, but the difficulty of scoring the somewhat poorly sporulating $\operatorname{ser} B 2$ colonies for colour made it impossible to assess the number of whi-I93 serB2 recombinants. However, examination of the gradient of allele frequencies given in Table 4 reveals that whi-r93 is nearer than ser $B 2$ to $m t h B$. The location of whi-r 93 between $\operatorname{str} A$ and $\operatorname{ser} B$ unambiguously defines a new whi locus, termed whic.

Mutations located in the strA-cysC region. Hopwood et al. (1970) noted that the majority of the whi mutations they examined were located in the strA-cysC interval. Of the 50 whi mutations whose mapping is described in the present paper I found that $4 \mathrm{I}$ mapped in this region in preliminary crosses (Table 2). Differences in the linkage of some of these mutations with cysC suggested that several loci were represented, a possibility confirmed in crosses described below. For clarity the mutations will be considered in three separate sections. 
Table 6. The location of whi-107 and -124

The strains involved and selection imposed (indicated by triangles) in these crosses are indicated in the diagrams, which also contain allele frequencies (percentage) abstracted from the summed data for crosses with both whi mutations.

Diagram of cross

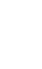

Genotype

whi

Wild-type

leuB5

leuB5 whi

$w h i$

hisD3 whi

hisD3

Wild-type

$100 \quad 53$

47

0

100

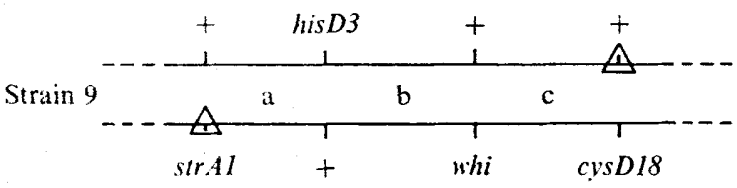

$100 \quad 65$

54

0

hisD3

Wild-type

whi

hisD3 whi

Crossovers in interval

Frequency in crosses

$\overbrace{w h i-107}^{\text {with }}{ }_{w h i-124}$

a

50

48

b

22

18

c

24

33

$\mathrm{a}, \mathrm{b}, \mathrm{c}$

0

0

Totals $\overline{96}$

$\overrightarrow{99}$

a

22

b

10

c

23

69

a, b, c

Totals $\overline{51}$

$\overline{151}$

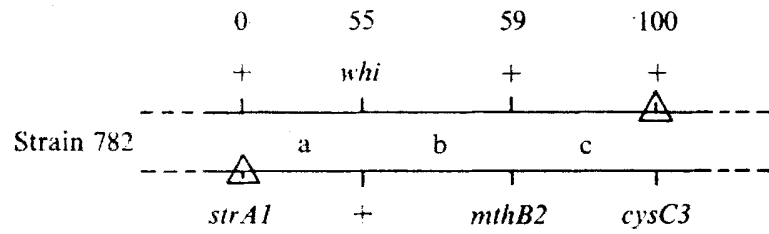

whi

Wild-type

$m t h B 2$

$m$ mhB2 whi

41

0 a

b

c

a, b, c

Totals $\overline{295}$
$100 \quad 45$

Totals 
whi-16. Preliminary mapping indicated that whi-I6 (phenotypic class VI) was located closer to $\operatorname{str} A$ than to $c y s C$. This was confirmed in a cross of whi-16 with strain 782, in which selection was made for recombinants resulting from crossing-over in the interval between strA and $c y s C$, which contained in addition to whi-16 the marker mthB2 (Table 5). Wildtype recombinants were very common, and whi-I6 mthB2 recombinants very rare, so it was concluded that whi-I6 was located between $\operatorname{str} A$ and $m \operatorname{th} B$. In a further cross of whi-I6 against strain V3I selection was made for recombinants arising from crossing-over in the strA-mthB interval, which included the marker uvsB6 (Table 5). Wild-type recombinants were again common and the reciprocal $u v s B$ whi-r6 class rare, giving the gene sequence strA-whi-16-uvsB. This identified another previously unknown whi locus, termed whiD (Fig. 5).

whi-107 and-124. A series of crosses was made with the strains whi-ro7 and -r24 (phenotypic class VI) in all of which selection was made for recombinants resulting from crossingover in the region between $\operatorname{str} A$ and cys $C$ or $D$. The segregation of leuB, his $D$ or mthB (depending on the strain used) was then examined in relation to that of the whi mutations (Table 6). Where leuB was segregating the abundance of $w h i^{+} l e u B^{+}$and the absence of whi leuB6 recombinants indicated that both whi mutations were located between strA and leuB. In contrast, in crosses involving the his $D$ gene, $w h i^{+}$his $D^{+}$recombinants were rare, and the reciprocal whi his $D_{3}$ class quite common, giving the sequence strA-his $D$-whi. This was confirmed for whi-ro7 in a cross in which the same selection was applied, but the coupling arrangement was different, so that the more frequently occurring informative class was $w h i^{+}$his $D^{+}$. Finally, the segregation of $w h i-107$ and -124 with respect to $m t h B 2$ was examined, again in the same selective conditions. The critical recombinant classes were rare, indicating close linkage between $m t h B 2$ and the whi mutations; among the critical recombinants, $m t h B^{+} w h i^{+}$greatly outnumbered $m t h B 2$ whi, giving the sequence $s t r A r$-whi-mthB2. It was thus concluded that whi-107 and -I24 identified a new whi locus, whiE (Fig. 5), mapping between the closely linked loci his $D$ and $m t h B$.

Mutations in the leuB-cysC interval. Crosses with strain 1107 or $\mathrm{JI} 92$ (Table 7 ) served to locate the remaining 38 whi mutations between $l e u B$ and $c y s C$, on the criterion that selection for recombinants arising from crossing-over between $\operatorname{str} A$ and $c y s D$ gave an excess of leuB whi over leuB $B^{+}$whit recombinants. However, the extent of this excess varied widely, its significance being particularly difficult to assess where informative recombinants were rare. In some cases (cross-type B, Table 7) their relative numbers were increased by selecting for recombinants arising from crossing-over in the shorter interval $m t h B$ to cys $D$, utilizing $m t h B 2$ whi recombinants obtained in other crosses. In Table 7 the crosses have been roughly separated into two groups, the first comprising those in which whi recombinants occurred relatively frequently among the leuB progeny, and the second those in which $l e u B w h i^{+}$were three or more times more frequent than leuB whi recombinants. This was done because, taking the ratio of whi:whi+ among leuB recombinants to be related to the ratio of the distances leuB-whi:whi-cysC, these two groups probably represented at least two distinct whi loci, one of which was closely linked to leuB.

In order to clarify the linkage relationships of whi mutations in the leuB-cysCD interval, a series of recombinants was isolated in which whi mutations were coupled with either leuB2 or cys DI8. Table 8 contains data obtained from a permutation of crosses of such strains involving three representative whi mutations: whi-7I, $-I I 9$, and $-I 7$ (phenotypic classes I, III and IV respectively). Selection was made for recombinants arising by crossing-over in the leuB-cysC interval. For each of the three heterologous pairs of mutations whi+ ${ }^{+}$recombinants were found in appreciable numbers in one coupling arrangement only, in which they could 
Table 7. The location of whi mutations between leuB and cys $D$

Each whi mutant or its $m t h B 2$ derivative was crossed with strains 1107 or $\mathrm{J} 192$ and $c y s D^{+}$and strAI (cross-type A) or $m t h B^{+}$(cross-type B) were selected, with the exception of the cross involving whi-244, in which a hisAI whi-244 strAI strain was used, and selection was made for cys $D^{+}$and $h i s A^{+}$. The results have been divided into those giving comparable numbers of leuB5 whi and leuB5 whit recombinants, and those in which leuB5 whi+ recombinants were three or more times more frequent than leuB5 whi ones.
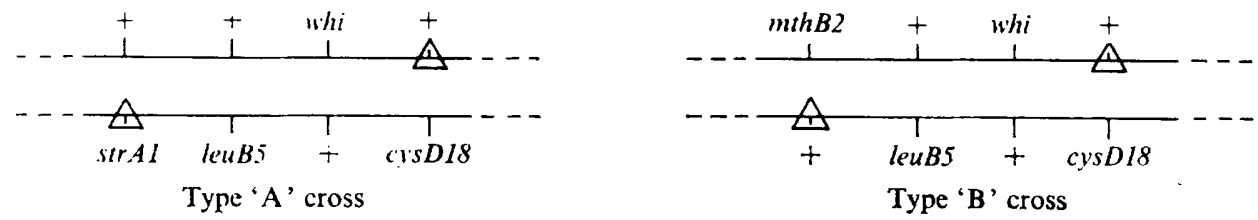

Frequency of recombinant classes

\begin{tabular}{|c|c|c|c|c|c|c|}
\hline $\begin{array}{l}\text { whi } \\
\text { mutation }\end{array}$ & $l e u B 2$ & $\begin{array}{c}\text { leuBz } \\
\text { whi }\end{array}$ & whi & wild type & $\begin{array}{l}\text { Total number of } \\
\text { recombinants scored }\end{array}$ & $\begin{array}{l}\text { Type of } \\
\text { cross }\end{array}$ \\
\hline$* 6$ & 11 & 13 & 175 & I & 200 & A \\
\hline & 13 & II & 173 & I & 188 & $\mathbf{A}$ \\
\hline$I 7$ & $\{13$ & $4 I$ & 45 & 0 & 99 & B \\
\hline 36 & II & 28 & 61 & 0 & 100 & $\bar{A}$ \\
\hline & 117 & 32 & 151 & 0 & 200 & A \\
\hline 40 & 28 & 27 & 43 & 0 & IOI & B \\
\hline${ }^{*} 46$ & 38 & 20 & 134 & 6 & 198 & A \\
\hline 62 & 1 & 13 & 234 & 1 & 249 & A \\
\hline 80 & 81 & 45 & 103 & 6 & 235 & B \\
\hline 87 & 4 & 4 & 17 & 0 & 25 & A \\
\hline 95 & 28 & 31 & 22 & 0 & $8 I$ & B \\
\hline 103 & 46 & 23 & $2 \mathrm{I}$ & 0 & 90 & B \\
\hline 109 & 30 & 18 & 97 & I & 146 & $\mathrm{~A}$ \\
\hline 119 & 45 & $4 I$ & 64 & 0 & 150 & A \\
\hline 122 & 8 & 25 & 66 & I & 100 & A \\
\hline 180 & 70 & 29 & 2 & 0 & IOI & B \\
\hline 197 & 23 & $4 I$ & 83 & 0 & 147 & A \\
\hline 219 & 46 & 21 & 13 & 0 & 80 & B \\
\hline 225 & 20 & 38 & 20 & 0 & 78 & B \\
\hline 226 & 32 & 29 & 27 & 0 & 88 & $\mathbf{B}$ \\
\hline 229 & 35 & $3 I$ & 22 & 0 & 88 & B \\
\hline 235 & 30 & 57 & I I I & 2 & 200 & A \\
\hline 244 & 5 & I I & 71 & 0 & 87 & See legen \\
\hline 10 & 73 & 5 & 24 & 0 & 102 & B \\
\hline$I I$ & 83 & 5 & 10 & I & 99 & A \\
\hline $3 I$ & 31 & 2 & 15 & 0 & 48 & A \\
\hline & 170 & 2 & 23 & 2 & 97 & A \\
\hline 60 & $\{44$ & 3 & 3 & 0 & 50 & B \\
\hline 64 & 73 & 6 & 24 & 0 & 103 & B \\
\hline & 188 & 2 & I I & 0 & IOI & $\mathbf{A}$ \\
\hline 65 & $i_{148}$ & 5 & 51 & 0 & 204 & B \\
\hline & 1 66 & 2 & 32 & 0 & 100 & A \\
\hline 71 & $\{332$ & 7 & 29 & 3 & 37 I & B \\
\hline & 49 & 7 & 28 & 2 & 86 & A \\
\hline 75 & $\{86$ & 9 & 14 & 0 & 109 & B \\
\hline 97 & 25 & 7 & 67 & 0 & 99 & A \\
\hline 99 & 256 & I I & 33 & I & 301 & B \\
\hline 100 & 39 & 6 & 35 & 0 & 80 & B \\
\hline 125 & 77 & I & 8 & 0 & 86 & B \\
\hline 148 & 158 & 12 & 35 & 0 & 205 & B \\
\hline 172 & 39 & 3 & 48 & 0 & 90 & A \\
\hline 209 & 42 & 7 & 34 & 0 & 83 & A \\
\hline 242 & 79 & 15 & II & 0 & 105 & B \\
\hline 250 & 106 & 20 & 15 & I & 142 & B \\
\hline
\end{tabular}

* Data of Hopwood et al. (1970). 
Table 8. Identification and ordering of three whi loci mapping between leuB5 and cysDI8

A complete permutation of crosses was carried out between recombinant derivatives of whi-I $7,-7 I$ and -rrg containing leuBs or $c y s D r 8$, with selection for $l e u B^{+}$and $c y s D^{+}$. The recombinants were classified as whi or whit either on the primary selective plates or, where leaky parental growth obscured colony colour, after restreaking. The crosses were set up from spore suspensions which were also tested for reversion of auxotrophic and morphological markers. In no case were the observed reversion rates higher than $10^{-4}$ for leuB5 or cys DI8, or $10^{-2}$ for whi mutations, per plating unit. (These limits represented practical limitations. The actual reversion rates were probably of a much lower order.)

Crossovers required to generate $w h i^{+}$recombinants

\section{Number \\ of $w h i^{+}$}

recombinants

(\%) Number of
recombinants
scored
Favoured gene sequence
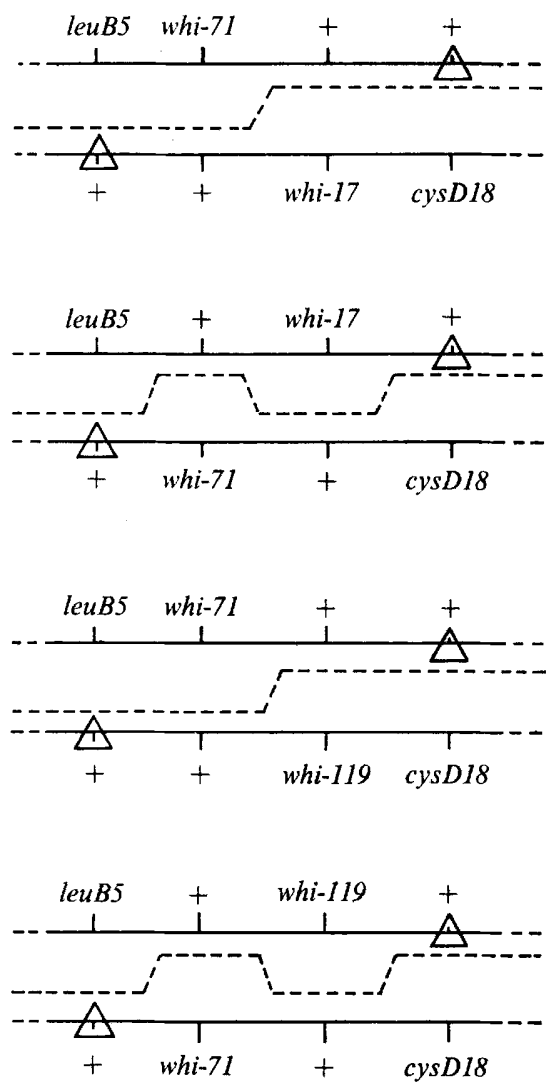

leuB - whi-71

- whi-119-cysD
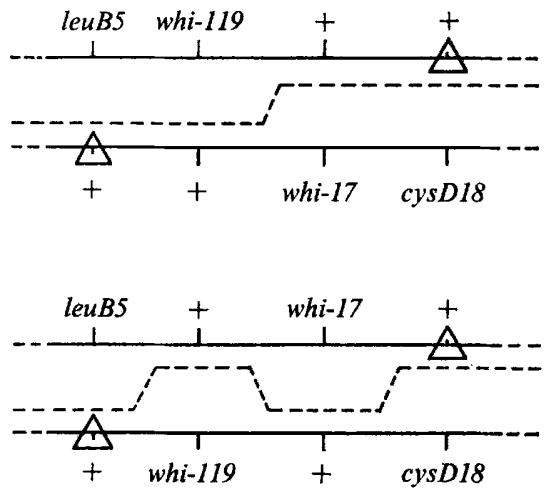
Table 9. Whi mutations located between leuB and cysD: their mapping with respect to whi-7I, -II9 and -17

All crosses were made as described in Table 8 . The results are arranged in three groups, the members of which were located close to whi-7I, $-I I 9$ and $-I 7$ respectively. Classification of phenotypes was as described earlier in the text.

whi mutation coupled with leuBs (or *mthB2)
Number (\%) of $w h i^{+}$recombinants with

\begin{tabular}{|c|c|}
\hline 10 & 0 \\
\hline $3 I$ & 0 \\
\hline 60 & 0 \\
\hline 64 & 0 \\
\hline $7 I$ & 0 \\
\hline 75 & 0 \\
\hline 97 & 0 \\
\hline 99 & 2 \\
\hline 100 & I \\
\hline${ }^{*} 103$ & 0 \\
\hline 125 & 0 \\
\hline 172 & 0 \\
\hline 209 & 0 \\
\hline$I I$ & 0 \\
\hline 109 & - \\
\hline 119 & 0 \\
\hline 197 & 0 \\
\hline 219 & 0 \\
\hline 242 & - \\
\hline 250 & 0 \\
\hline 6 & 0 \\
\hline 17 & 0 \\
\hline 36 & 0 \\
\hline 40 & I \\
\hline 46 & 0 \\
\hline 62 & 0 \\
\hline 80 & 0 \\
\hline 87 & 0 \\
\hline 95 & 0 \\
\hline 122 & - \\
\hline 225 & 0 \\
\hline 226 & 0 \\
\hline 229 & 0 \\
\hline 235 & - \\
\hline 244 & 0 \\
\hline
\end{tabular}

cys DI8
8
77
47
90
89
79
8
75
86
34
8
79
86
4
4
35
3
5
27
4

presumably be generated by a single crossover in the leuB-cys $D$ interval. This permitted an unambiguous ordering of the three mutations, whi-7I being located close to leuB, whi-I7 close to $c y s D$, and whi-II9 approximately midway between the leu and cys genes.

Having established this basic map, the cysDr8 strains containing whi-7r, $-I I 9$ and $-I 7$ were crossed with leuB5 strains containing most of the other whi mutations mapping in the leuB-cys $D$ interval, again with selection for $l e u B^{+}$and $c y s D^{+}$. The frequencies of whit recombinants are given in Table 9. Each leuB5 whi strain showed the same recombination pattern as one of the three leuB whi strains listed in Table 8 had done. Those listed in the first part of Table 9 resembled leuB5 whi-7I in giving no whi+ recombinants with cysDI8 whi-7I, about 30 to $50 \%$ with cysDI8 whi-II9, and about 80 to $90 \%$ with cys $D_{1} 8$ whi-I7; those in the second part of Table 9 resembled leuB5 whi-II9 in giving no whi $i^{+}$recombinants with cysDI8 whi-7I or -119 , but about 30 to $50 \%$ with cysDI 8 whi-I7; and those in the third 
part of the Table resembled leuB5 whi-I7 in giving no $w h i^{+}$recombinants with any of the tester strains.

A few whi mutations were also obtained in combination with cys $D_{1} 8$ and crossed with $l e u B 5$ tester strains carrying whi-7I, $-I I 9$ and $-I 7$ respectively (results not tabulated). The cys DI8 strains carrying whi-65, $-99,-125,-148$ and -180 all failed to give $w h i^{+}$recombinants with any of the testers. These whi mutations were thus located close to whi-7I, confirming the evidence in Table 9 for whi-99 and -125 , and giving locations for whi-65, -148 and -180 of which leuB5 derivatives were not available. The location of whi-80 close to whi-I 7 was also confirmed in crosses of cysDr8 whi-80 with the leuBs whi tester strains: $88 \%$ whit recombinants were obtained with leuB5 whi-7I, 47\% with leuB5 whi-II9 and none with leuB5 whi-I7.

Excluding whi-99, we may conclude that of the 37 mutations examined 15 were located in a cluster close to leuB, 15 in a cluster close to $c y s D$ and seven in a cluster midway between $l e u B$ and cys $D$. With the exception of whi-209 (class III), all mutations in the first group had class I phenotype and were assigned to the whiG locus; mutations in the group closely linked to cys D had class III or IV phenotype and were assigned to the whil locus; and all mutations in the intervening group had class III phenotype and defined the whiH locus.

On the strength of its unique phenotype (class V) whi-99 was taken to represent a distinct locus, whiF, very closely linked to $w h i G$.

\section{DISCUSSION}

To permit correlation of the two classifications - morphological and genetic - of white colony mutants, the data have been summarized in Fig. 5. Eight distinct map locations, designated whi $A, B, C, D, E, G, H$ and $I$, have been identified, and with a few exceptions mutations in any one location give rise to similar aerial mycelium structure. The exceptions may arise partially from the roughness of the classification; however, Hopwood et al. (I970) found that the mutations whi-6 (class IV phenotype) and whi-46 (class III phenotype), both of which map at the whil locus, were ultrastructurally distinct in that whi-6 had abnormally widely spaced sporulation septa while $w h i-46$ had none. This emphasizes the possibility that some of the clustered mutations found in this study may prove to be non-allelic if genetic functional tests can be applied. Such tests have so far been difficult to carry out either by the use of heteroclones (Hopwood, 1967) or by a technique exploiting the different filterability of wild-type spores and the aerial growth of whi mutants of phenotypic classes I-IV (K. F. Chater, unpublished). In the case of whi-99, the great difference between its phenotype (class V) and that of all the other mutations closely linked to it at the whiG locus (class I) seems sufficient to justify the assumption that whi-99 is a mutation in a distinct gene, whiF.

Since several of the whi loci are represented by only one or two mutations, it is reasonable to assume that more loci await discovery, and that the system is genetically more complex than the previous study by Hopwood et al. (1970) had indicated. A more rational approach to the search for further loci and to the selection of representative mutants for fine structure and biochemical analysis should be facilitated by this study.

The distribution of whi loci on the linkage map (Fig. 5) is similar to that of auxotrophic, resistance and temperature-sensitive mutations (Hopwood, 1966, 1967) in that no whi mutations lie in either of the two 'silent' regions: in Bacillus subtilis, one previously genetically silent region has recently been found to contain many of the genes involved in sporulation (Ionesco, Michel, Carmi \& Schaeffer, 1970). Presumably the silent regions of Streptomyces coelicolor are either composed of integrated extraneous genetic material such 
as prophages (e.g. $\phi \mathrm{C}_{3} \mathrm{I}$; Lomovskaya, Emeljanova \& Alikhanian, 197I) and episomes, or they represent recombinational 'hot spots' as discussed by Hopwood (1967).

I am grateful to Judith Humphries and Frances Dixon for their excellent technical assistance and to Professor D. A. Hopwood for his suggestions and criticisms and for allowing me free access to his strains and unpublished results.

\section{REFERENCES}

Delić, V., Hopwood, D. A. \& Friend, E. J. (1970). Mutagenesis by $N$-methyl- $N$ '-nitro- $N$-nitrosoguanidine (NTG) in Streptomyces coelicolor. Mutation Research 9, 167-182.

Demerec, M., Adelberg, E. A., Clark, A. J. \& Hartman, P. E. (1966). A proposal for a uniform nomenclature in bacterial genetics. Genetics $54,61-76$.

HAROLD, R. J. \& Hopwood, D. A. (1970a). Ultraviolet sensitive mutants of Streptomyces coelicolor. I. Phenotypic characterisation. Mutation Research 1o, 427-438.

Harold, R. J. \& Hopwood, D. A. (1970b). Ultraviolet sensitive mutants of Streptomyces coelicolor. II. Genetics. Mutation Research 10, 439-448.

Hopwood, D. A. (1959). Linkage and the mechanism of recombination in Streptomyces coelicolor. Annals of the New York Academy of Sciences 8r, 887-898.

Hopwood, D. A. (1966). Non-random arrangement of temperature-sensitive mutants on the linkage map of Streptomyces coelicolor. Genetics 54, II69-1 176.

Hopwood, D. A. (1967). Genetic analysis and genome structure in Streptomyces coelicolor. Bacteriological Reviews 31, 373-403.

Hopwood, D. A. (1970). Linkage map and list of markers of Streptomyces coelicolor. In Handbook of Biochemistry, Selected Data for Molecular Biology, 2nd edn. Edited by H. A. Sober. Ohio: Chemical Rubber Company.

Hopwood, D. A., Harold, R. J., Vivian, A. \& Ferguson, H. M. (1969). A new kind of fertility variant in Streptomyces coelicolor. Genetics 62, 461-477.

Hopwood, D. A. \& Sermontr, G. (1962). The genetics of Streptomyces coelicolor. Advances in Genetics II, 273-342.

Hopwood, D. A., Wildermuth, H. \& Palmer, H. M. (1970). Mutants of Streptomyces coelicolor defective in sporulation. Journal of General Microbiology 6r, 397-408.

Ionesco, H., Michel, J., Cami, B. \& Schaeffer, P. (1970). Genetics of sporulation in Bacillus subtilis Marburg. Journal of Applied Microbiology 33, 13-24.

KUTZNER, H. J. \& WAKSMAN, S. A. (1959). Streptomyces coelicolor Müller and Streptomyces violaceoruber Waksman and Curtis, two distinctly different organisms. Journal of Bacteriology 78, 528-538.

Lomovskaya, N. D., Emeluanova, L. K. \& Alikhanian, S. I. (1971). The genetic location of prophage on the chromosome of Streptomyces coelicolor. Genetics 68, 34I-347.

VIvian, A. \& Hopwood, D. A. (1970). Genetic control of fertility in Streptomyces coelicolor A3(2): the IF fertility type. Journal of General Microbiology 64, 101-1 I7.

WiLdermuth, H. \& Hopwood, D. A. (1970). Septation during sporulation in Streptomyces coelicolor. Journal of General Microbiology 60, 5I-59.

Williams, S. T. \& DAvits, F. L. (1967). Use of a scanning electron microscope for the examination of Actinomycetes. Journal of General Microbiology 48, I7I-1 77. 